\title{
Caso y novela. Sobre la diferenciación entre el Derecho y la literatura en la Italia medieval tardía*
}

\section{Casus and Novella. About the Differentiation between Law and Literature in the Late Medieval Italy}

\section{Pia Claudia Doering}

Westfälische Wilhelms-Universität Münster

ALEMANIA

pia.doering@uni-muenster.de

[Hipogrifo, (issn: 2328-1308), 9.2, 2021, pp. 45-61]

Recibido: 16-02-2021 / Aceptado: 12-03-2021

DOI: http://dx.doi.org/10.13035/H.2021.09.02.05

Resumen. Este artículo aborda las similitudes y la competencia entre poetas y juristas que surgieron en la Italia medieval tardía. Tomando como ejemplo la novela X, 4 del Decameron de Boccaccio se mostrará cómo la práctica jurídica y la narración novelística se entrelazan estrechamente, lo que da lugar a una perspectiva profundamente crítica del derecho por parte de la literatura.

Palabras clave. Caso; novella; disputatio; Boccaccio; poeta-jurista; Bolonia.

Abstract. This article is dealing with similarities and competitions between poets and legal experts, as they emerged in late medieval Italy. Using the novella X, 4 of Boccaccio's Decameron as an example, it will be shown how closely legal practice and novelistic narration are interwoven and how this entanglement gives rise to a profoundly critical perspective of law on the part of literature.

Keywords. Casus; novella; disputatio; Boccaccio; Poet-lawyer; Bologna.

* La autora expresa su más sincero agradecimiento al Profesor Rafael Ramis Barceló, por sus valiosos comentarios. Agradece también a la Dra. María Eugenia Escobar Bravo la traducción del artículo a la lengua española y a Antonio Ruiz Arranz la revisión final del manuscrito. 


\section{INTRODUCCIÓN}

El Derecho y la literatura siempre han mantenido una relación compleja entre sí. En el campo del Derecho, la Italia medieval desempeñó un papel pionero para toda Europa. La Universidad de Bolonia se convirtió, en el siglo XII, en el centro occidental más importante para el estudio del Derecho romano y canónico. La misma atracción que París ejerció sobre los teólogos y filósofos la ejerció Bolonia sobre los juristas ${ }^{1}$. La relación entre poetas y juristas también se gestó en Italia y, durante mucho tiempo, ejerció su influencia más allá de las fronteras de aquel país. Las similitudes entre ambas disciplinas eran claramente evidentes; entre ellas destacaba, por ejemplo, el interés por el lenguaje y la retórica, así como el fomento de la lengua vernácula. Tales puntos en común no impidieron que, al mismo tiempo, incrementase el recelo y la crítica entre ambas facciones; lo que fue favorecido por el rápido ascenso social de los juristas que, a su vez, los convirtió en blanco de la crítica literaria y la sátira.

El presente artículo pretende ilustrar, en primer lugar, las tensiones y los puntos de encuentro entre poetas y juristas en la Italia medieval tardía, conforme estos se fueron desarrollando. A continuación, se tratará de mostrar, a partir del estudio de un "caso práctico" - la novela X, 4 del Decamerón, de Boccaccio- la íntima conexión que la práctica jurídica y la narrativa novelesca mantenían entre sí; y cómo ese entrecruzamiento entre ambas disciplinas originó un tratamiento profundamente crítico de la literatura hacia el Derecho.

\section{SimiLitUdes ENTRE EL DERECHO Y LA LITERATURA EN LA EDAD MEDIA}

La principal similitud entre los poetas y juristas se encontraba en el dominio del lenguaje y la retórica. En este sentido, el interés del joven Giovanni Boccaccio por los estudios lingüísticos llevó a su padre a proporcionar a su hijo una formación jurídica:

Satis enim memini apposuisse patrem meum a pueritia mea conatus omnes ut negociator efficerer, meque, adolescentiam nondum intrantem, arismetrica instructum, maximo mercatori dedit discipulum, quem penes sex annis nil aliud egi quam non recuperabile tempus in vacuum terere. Hinc quoniam visum est, aliquibus ostendentibus indiciis, me aptiorem fore licterarum studiis, iussit genitor idem, ut pontificum sanctiones, dives exinde futurus, auditurus intrarem, et sub preceptore clarissimo fere tantundem temporis in cassum etiam laboravi. Fastidiebat hec animus adeo, ut in neutrum horum officiorum, aut preceptoris doctrina, aut genitoris autoritate [...] aut amicorum precibus seu obiurgationibus inclinari posset, in tantum illum ad poeticam singularis traebat affectio!? 
A pesar del tópico recurrente de la inutilidad de estudiar Derecho ${ }^{3}$, el pasaje autobiográfico de la Genealogia deorum gentilium muestra las similitudes existentes dentro del proceso formativo de poetas y juristas: a todos ellos se les exigía el dominio del Trivium, esto es, de las "artes orales", de la gramática, la retórica y la dialéctica.

Asimismo, en el ars dictaminis, los juristas no solo se ejercitaban en confeccionar escritos forenses, sino que también se les instruía en el arte del lenguaje en general; de este modo, su formación no se centraba únicamente en adquirir maestría en el en el lenguaje jurídico-técnico, sino que en ella también cultivaban la poesía romana. Otro de los puntos compartidos por poetas y juristas aludía a su interés por la lengua vernácula: en Italia, los juristas contribuyeron de manera significativa a la imposición del volgare. En este sentido, el Derecho romano contemplaba el empleo de varias lenguas, con la condición de que todas las partes lo entendieran ${ }^{4}$. En los textos legales como sentencias, contratos, escrituras, juramentos, laudos arbitrales, informes de testigos y privilegios, se pueden encontrar las primeras evidencias de la lengua vernácula ${ }^{5}$. Además, los juristas estuvieron entre los primeros lectores y promotores de la literatura en lengua popular ${ }^{6}$. Ahora bien, no se limitaron a recibir acríticamente las obras poéticas, sino que ellos mismos se dedicaron a componer, surgiendo en este periodo el perfil del poeta-jurista. En Palermo, el emperador Federico II de Hohenstaufen (1194-1250) incentivó las actividades literarias de sus funcionarios. Y a la cabeza de la escuela siciliana de poetas, que después daría forma a la lírica italiana a partir de Petrarca, estaba Giacomo da Letini (fallecido antes de 1250), quien firmaba los documentos legales y las cartas, así como sus poemas, como «Notaro Giacomo» o «Jacobus notarius», nombres bajo los cuales pasaría a la historia literaria?

\footnotetext{
3. Petrarca explica también en varias cartas que solo estudió Derecho a petición de sus padres y que le pareció una pérdida de tiempo. Por ejemplo, la Carta XX, 4, 3-4 de los Familiares dice: «Ego quidem, amice, illi studio puer destinatus a patre, VIX duodecimum etatis annum supergressus et ad Montem Pessulanum primo, inde Bononiam transmissus, septennium in eo integrum absumpsi, eiusque quoad per etatem et ingenium licuit, rudimenta percepi. Cuius temporis an me hodie peniteat si roger, heream; nam et vidisse omnia, si liceat, velim, et tantam perexigue vite partem effluxisse michi doleo dumque aliquid vite supererit dolebo. Aliud agere per eos annos potui sive nobilius sive nature mee aptius».

4. Así, en Institutiones, 3.15.1, se indica lo siguiente respecto del lenguaje permitido ante una stipulatio (o estipulación), es decir, una obligación contraída verbalmente mediante frases solemnes y preestablecidas: «utrum autem Latina an Graeca vel qua alia lingua stipulatio concipiatur, nihil interest, scilicet si uterque stipulantium intellectum huius linguae habeat».

5. Véase Kapp, 2007, p. 6

6. Dionisotti (1995, p. 58) subraya que el desarrollo de la literatura en lengua vernácula en Italia debe mucho, en gran medida, a la «iniziativa di laici educati allo studio e alla pratica delle leggi, a giudici e notai». 7. Véase De Propris, 2000.
} 


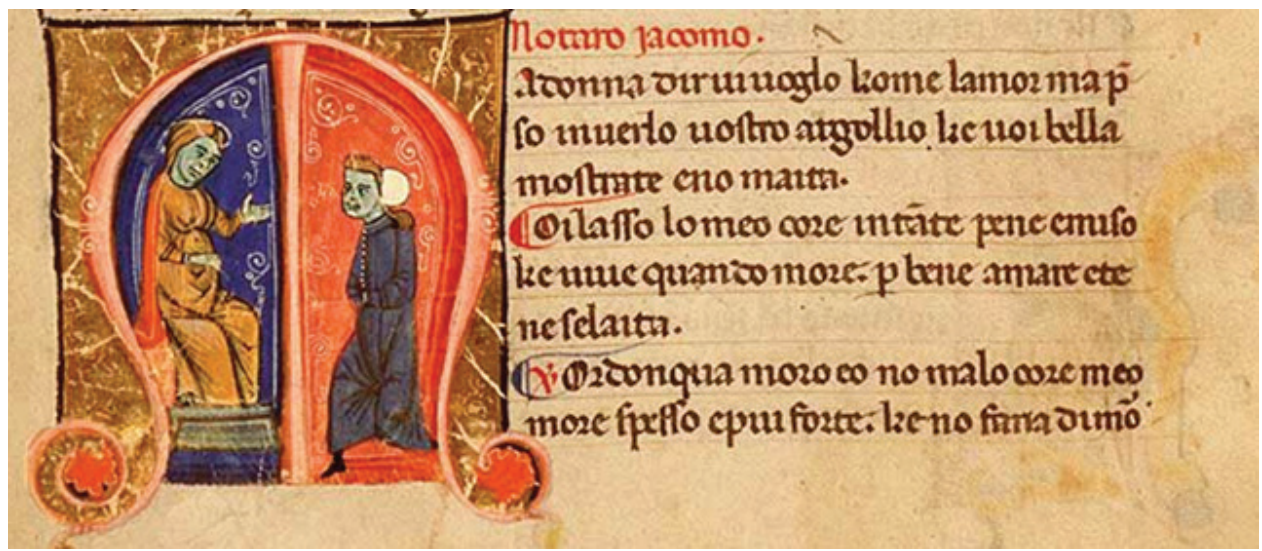

Fig. 1. Iluminación de la canzone «Madonna, dir vi voglio» en el manuscrito Palatino 418, hoy Banco Rari 217, fol. 21v, en la Biblioteca Nazionale Centrale di Firenze. Sobre el texto literario está escrito «Notaro Jacomo», resaltado en rojo. Se acentúa así la formación jurídica del autor

El perfil de poeta-jurista también jugó un papel destacado en el segundo período de auge de la poesía lírica italiana medieval, en la poesía del Dolce Stil novo, que llegó a la Toscana desde Bolonia: casi todos los poetas de esta escuela eran juristas, entre los que se encontraba Cino da Pistoia (ca. 1270-1336) que, en 1314, obtuvo el laurea de doctor iuris en Bolonia y luego enseñó en Treviso, Siena, Perugia y Nápoles.

La proximidad de los juristas y los poetas condujo a que la argumentación jurídica penetrase en la literatura. Así, al poeta-jurista Giacomo da Lentini se le atribuye la invención del soneto, que reproduce el movimiento de razonamiento triple, propio del silogismo ${ }^{8}$. También la novela surgió como género narrativo en el contexto del Derecho. La influencia jurídica en la novela se manifestó, primero, en el plano de la historia de las palabras: en el Corpus iuris civilis del Emperador Justiniano (482-565), el término (leges) novellae abarcaba aquellos suplementos y leyes individuales donde se regulaban nuevos casos imposibles de subsumir en las constitutiones antiguas. Esa imposibilidad de resolver un nuevo supuesto con la ayuda del Derecho existente es revelador de la conexión estructural con la novela literaria: a diferencia de los ejemplos, las vidas o los fabliaux, cuyos contenidos pueden clasificarse como típicos y regularmente anclados a una base común, la novela describe unos sucesos tan complejos como únicos, para cuya resolución aún no existen cánones ${ }^{9}$. De este modo, el género literario de la novela reproducía el mismo patrón definitorio de la novela jurídica: la excepción representada por un caso singular respecto a la regla general y la dificultad para su clasificación y evaluación; lo que exigía recurrir a nuevas pautas narrativas ${ }^{10}$.

8. Véase Friedrich, 1964, p. 32.

9. Véase Neuschäfer, 1969, pp. 33-51.

10. Véase Rath, 2008, p. 58. 
En su construcción formal, la novela estaba influenciada por el método de la disputatio, desarrollado por los juristas medievales. En efecto, la forma particular del texto en la quaestio disputata se estableció en la legística del siglo XII y, unas décadas más tarde, también en la canonística ${ }^{11}$. Su génesis muestra cierta proximidad con el comentario, que también utiliza la forma de quaestio. Las disputatios jurídicas, tanto en forma oral como escrita, solían comenzar con la presentación de un caso jurídico concreto (casus). A partir de él, se planteaban una o varias preguntas. Tras ello, se añadían argumentos a favor y en contra, para terminar con la solutio, y una última refutación de los argumentos conflictivos ${ }^{12}$. En el episodio Questioni d'amore de su primera novela en prosa, el Filocolo, Boccaccio desarrolla la concepción literaria de las "cortes de amor", sirviéndose de los elementos propios de la disputa legal, el casus y la quaestio ${ }^{13}$. La estructura narrativa del pleito, que la audiencia trata de forma controvertida y finalmente juzga, se denomina aquí novelle ${ }^{14}$. En el Proemio del Decamerón, Boccaccio, de nuevo, define la novela con referencia al concepto de casus ${ }^{15}$. De la presentación narrativa del caso tanto en el Filocolo como, sobre todo, en el Decamerón destaca que esta se desprenda de su función pragmática, para convertirse en una narrativa autónoma ${ }^{16}$.

\section{EL ASCENSO SOCIAL DE LOS JURISTAS}

La proximidad del Derecho con la poesía, resultante de sus similitudes, originó disputas entre sus protagonistas, y desencadenó una actitud recíprocamente crítica entre los dos campos, sus representantes y sus métodos.

Los juristas del medioevo tardío lograron un brillante avance social. Aspiraban a una posición dominante tanto en el Estado como en la Iglesia, y en la jerarquía universitaria. Como asesores generosamente pagados al servicio de reyes y Papas, ganaron prestigio e influencia ${ }^{17}$. El incremento de los actos jurídicos cotidianos les permitió estar presentes en todos los ámbitos de la sociedad. Los mismos juristas justificaron teóricamente su importancia para el Estado recurriendo, entre otros

11. Véase de Boer, 2018, p. 221.

12. Véase de Boer, 2018, p. 233.

13. Sobre la influencia del discurso jurídico en las questioni d'amore del Filocolo véase Emmelius, 2010, pp. 153-197.

14. Fiammetta, por ejemplo, introduce su respuesta al caso presentado por Menedon y a la pregunta que de él se desprende con las palabras: «Bellissima è la novella e la dimanda» (Boccaccio, Filocolo, IV, 32, 1). 15. Véase Boccaccio, Decameron, Proemio, 14: «Nelle quali novelle [scilicet del Decamerón] piacevoli e aspri casi d'amore e altri fortunati avvenimenti si vederanno così ne' moderni tempi avvenuti come negli antichi». 16. Véase Emmelius, 2010, pp. 171-172. Como Emmelius ha demostrado (2010, pp. 297-331), una diferencia clave entre las novelas de las questioni d'amore del Filocolo y las novelas del Decamerón es que las primeras se dejan abiertas, en la medida en que concluyen con una cuestión todavía por tratar; mientras tanto, las novelas del Decamerón se cierran, al menos formalmente, con un final dentro de la propia historia. Sobre el lenguaje jurídico y el método legal en el Decamerón, véase Doering, 2020.

17. Lange, 2010, p. XI, considera que las grandes sumas de dinero que se abonaban por consultas legales dan buena cuenta de su importancia. Una minuta tan elevada «hätte man sich erspart, wenn es sich nach Ansicht der Zeit um belanglose Meinungsäußerungen einer käuflichen Juristenschicht gehandelt hätte». 
aspectos, al prólogo de las Instituciones de Justiniano. Así, la Constitutio Imperatoriam citaba a las armas y a las leyes como instrumentos de gobierno de igual jerarquía:

Imperatoriam maiestatem non solum armis decoratam, sed etiam legibus oportet esse armatam, ut utrumque tempus et bellorum et pacis recte possit gubernari et princeps Romanus victor existat non solum in hostilibus proeliis, sed etiam per legitimos tramites calumniantium iniquitates expellens, et fiat tam iuris religiosissimus quam victis hostibus triumphator ${ }^{18}$.

Los estudiosos del Derecho de la Baja Edad Media se basaron en este y otros pasajes similares para demostrar que los juristas eran (al menos) tan importantes para el buen gobierno como los soldados. De esa función sociopolítica, los juristas extrajeron una mejora de su estatus social ${ }^{19}$. En el debate sobre si la nobleza derivaba del linaje familiar o de la virtus del individuo, los juristas se inclinaban por la virtud del individuo, pero interpretando esa virtud como scientia, como dominio del aprendizaje legal20.

Los escritos no fueron el único medio con el que los juristas levantaron sus pretensiones nobiliarias; también acudieron a elementos visibles para la generalidad. Un vector importante de la puesta en escena de los juristas era su vestimenta, mediante la cual atraían la atención en la vida urbana y subrayaban su posición privilegiada. El color rojo de las togas y el petigrís, elementos tradicionalmente reservados a la nobleza, actuaban como resalto de lo que era la reivindicación social de una profesión que aspiraba a equipararse a la nobleza ${ }^{21}$.

El afán de prestigio social de los juristas provocó, eso sí, la oposición desde diferentes grupos: las críticas a los juristas, que a veces alcanzaba cotas de reprimenda, procedían de legos, otros grupos universitarios, así como de los poetas.

Las diatribas contra los juristas, como las de Petrarca y Boccaccio, cuestionaban su erudición, su enfoque metodológico y su postura moral. Como contrapunto a la imagen del jurista, los autores de estos escritos difamatorios oponían la figura

\section{Corpus luris Civilis, p. XIII.}

19. Según Fried (1974, p. 168), el sapiens, iurisperitus o legum doctor era plenamente consciente de su posición especial frente al plebeyo, el noble y el dignatario eclesiástico.

20. Sobre la reivindicación de los juristas para formar parte de la nobleza tanto desde una perspectiva general como en el contexto particular del debate acerca de la nobleza espiritual o de sangre, véase Lange, 1980 y Gilli, 2003, pp. 30-125. Gilli expone de forma convincente cómo los juristas logran argumentativamente «un passage assez clair de la noblesse-vertu à la noblesse-savoir» (2003, p. 66).

21. A mediados del siglo XIV, el famoso jurista Bartolo de Sassoferrato escribió el tratado De insigniis et armis que, en el contexto de la heráldica, también recurre a los colores y los ordena según una jerarquía. Debido a su luminosidad y su conexión con el elemento del fuego, Bartolo define el rojo como el segundo color más noble después del oro, que solo los miembros más distinguidos de la sociedad pueden llevar. Sobre las consideraciones de color en el tratado de Bartolo y su recepción véase Von Hülsen-Esch, 2006, pp. 97-103. 
del poeta y, con ello, el arquetipo de sabio formado extramuros de la universidad, que terminará impregnando el humanismo22.

\section{LOS TOPOI DE LA CRÍTICA LITERARIA A LOS JURISTAS}

Los elementos centrales de la crítica dirigida a los juristas por poetas como Petrarca y Boccaccio se introdujeron en la literatura, por un lado, a partir de críticas a la profesión jurídica realizadas por legos, así como por otros sectores humanistas rivales; por otro lado, fueron desarrolladas por los poetas, como contraposición a su propia creatividad y lugar en la sociedad.

Dentro de esa crítica cabe distinguir tres aspectos: 1) crítica de la puesta en escena y del lenguaje de los juristas, 2) crítica moral de su actitud interior, y 3) crítica del objeto y del método del Derecho.

La ambición de los juristas se reflejaba en su apariencia y vestimenta, lo que condujo a burlarse de ellos, retratándolos como unos "guaperas" vanidosos y carentes de ingenio.

El comienzo del capítulo de los juristas en la Geneologia deorum gentilium, de Boccaccio, está dedicado al atuendo de los juristas:

Sunt insuper homines quidam toga, aureis bullis et ornatu fere regio insignes, nec minus incessu et morum gravitate atque oris facundia spectabiles, magnis postergati clientum catervis et ingenti autoritate conspicui.

Para Cicerón, la sabiduría podía esconderse bajo un pobre manto, siendo el descuido de la apariencia parte del aspecto del filósofo ${ }^{23}$. De la pomposa apariencia de los juristas solo se podía inferir lo contrario: trivialidad.

Por su parte, el lenguaje de los juristas era regularmente criticado y caricaturizado. En particular, destacan tres aspectos: primero, a diferencia de los teólogos y los filósofos, se achacó a los juristas su recurso constante al "yo". En este sentido, por ejemplo, el canonista procedente de España o Portugal, Vicente Hispano, que enseñó en Bolonia entre 1210 y 1220, destacaba por frases como «Pero yo, Vicencio, digo» 24 . Junto con esa puesta en escena, también reflejada en el lenguaje, las críticas se dirigían, en segundo lugar, hacia la incomprensible jerga a la que había llegado el lenguaje jurídico. En tercer lugar, se criticaba que los juristas recurriesen a la retórica para perseguir objetivos amorales y distorsionar la verdad. Boccaccio hablaba de la «lingua venalis» ${ }^{5}$, o «lengua sobornable», de los juristas, y de su «lingua melliflua» ${ }^{26}$, de un lenguaje meloso, capaz de engañar. Aquí, la crítica lingüística se convertía en crítica moral. En general, a los juristas se les reprochaba que, en

22. Ver Gilli, 2003, pp. 17-27 y pp. 163-178.

23. Véase Cicero, Gespräche in Tuskulum, 3.23.56: «Saepe est etiam sub palliolo sordido sapientia». Sobre la diferente caracterización de los filósofos y los juristas véase Rexroth, 2018, pp. 304-309.

24. Ver Rexroth, 2018, p. 307.

25. Boccaccio, Genealogia deorum gentilium, XIV, 4, 8.

26. Boccaccio, De casibus virorum illustrium, III, 10 («In legistas ignavos»). 
sus asuntos, se mezclasen con lo abyecto o «lo nulo» ${ }^{27}$, y que cobrasen grandes sumas de dinero por su trabajo. En efecto, fue la aplicación práctica del Derecho lo que lo distinguió de la filosofía y la teología escolástica, poniendo a los juristas bajo la lupa de la codicia ${ }^{28}$. La aparición de los juristas y las formas de representación que eligieron favorecieron esa acusación. Boccaccio, en su De casibus virorum illustrium, dibuja una imagen sombría de los vicios de los juristas, en cuya cúspide se encontraba la avaricia:

Ex officinis igitur talibus [...] habemus ut plurimum assessores iudices et patronos, quibus unce sunt manus, impudici oculi, invicta luxuria, cor saxeum, ficta gravitas, lingua melliflua, dentes ferrei, et breviter auri insatiabilis appetitus ${ }^{29}$.

El vicio de la avaritia iba de la mano del propio fracaso de los juristas en su tarea real de hacer justicia. Y es que o bien - según la acusación de Boccaccio, que desarrolla narrativamente en las novelas del Decamerón- decidían conscientemente ejercer su oficio de forma amoral, por ejemplo, dejándose sobornar, persiguiendo fines viciosos o sembrando deliberadamente la discordia para sacar provecho de ella; o bien la avaricia nublaba sus facultades cognitivas, de modo que, simplemente, eran incapaces de discernir la realidad y actuar justamente. Además de la avaricia, Petrarca también criticó el utilitarismo de los juristas, que habría restado profundidad histórica a la ciencia jurídica de la época:

Quod idcirco diligentius feci, quia pars magna legistarum nostri temporis de origine iuris et conditoribus legum nichil aut parum curat, didicisse contenta quid de contractibus deque iudiciis ac testamentis iure sit cautum, ut que studii sui finem lucrum fecerit, cum tamen artium primordia et auctores nosse et delectatione animi non vacet et ad eius de quo agitur notitiam intellectui opem ferat; cum preterea ille mechanicarum proprius, liberalium vero et honestarum artium liberalior quidam et honestior sit finis. [...]

Quam venale mercimonium fecere! lingua illis, manus ingenium anima decus fama tempus fides amicitie, ad postremum omnia venalia, neque pluris precii quam par est. Et quam nulla proportio temporum ac morum! ${ }^{30}$

La objeción de Petrarca combina el reproche a la codicia, como vicio ante el que se someten todas las virtudes y acciones, con la crítica al método jurídico. Petrarca relega la jurisprudencia al nivel de las artes mechanicae, debido a la finalidad específica a la que se dirigía su método. Boccaccio hace una degradación similar, pero la construye desde la naturaleza de las normas legales. Las leyes sobre cuya base los juristas emitían sus opiniones no tenían validez universal, sino que variaban regionalmente y según el poder político, dependían de los propios juristas para su

27. En su Genealogia, XIV, 4,11, Boccaccio aporta ejemplos del uso puntilloso, cuando no moralmente bajo, del Derecho; así, los juristas diferenciaban «nunquid hereditario iure seu enphiteotico potius vel precario Titus vel Sempronius occupet agellum, nunquid certum debitum aut usurarium dicendum sit, nunquid ardens femina solvi posset a frigido viro».

28. Véase Rexroth, 2018, pp. 302-303.

29. Boccaccio, De casibus virorum illustrium, III, 10 .

30. Petrarca, Familiares, XX, 4, 21 y 24 
aplicación, y estaban sujetas a cambios a lo largo del tiempo ${ }^{37}$. En el sexto canto del Purgatorio, Dante ya critica lo efímero de las leyes en Florencia, que, promulgadas en octubre, perdían su fuerza vinculante en noviembre 32 . La mutabilidad de las leyes valió a Boccaccio, así como a otros rivales de los juristas, para negar que la jurisprudencia pudiera reivindicar la condición de sapientia y scientia. Teólogos, médicos y artistas mostraban sus dudas acerca de que los juristas dominasen realmente la doctrina aristotélica de la ciencia. En este sentido, el jurista boloñés Giovanni da Legnano (c. 1320-1383) tuvo que escuchar con disgusto que a los canonistas de París se les llamase asnos, por no utilizar correctamente la terminología aristotélica. Boccaccio tomó esta acusación y la hizo aún más afilada: además de asini, denominaba a los juristas «falerati onagri» ${ }^{33}$, lo cual significaba algo así como 'asnos salvajes con decoración'.

La caracterización del jurista en los polémicos escritos de Boccaccio y Petrarca contrasta con la representación de la figura del poeta. El poeta no se debía ni al poder ni al dinero. A diferencia del jurista, afincado en la ciudad, el poeta concebía la soledad como su hogar, y consagraba su vida a la contemplación, a cultivar la verdad y a la vida moralmente buena.

\section{LA RETÓRICA JURÍDICA Y EL AFÁN DE PODER: LA ESTRATEGIA DE MESSER GENTILE DE' CARISENDI (DECAMERÓN, $X, 4)$}

El ejemplo de la novela X, 4 del Decamerón muestra la compleja forma en la que los textos literarios adoptaban formas jurídicas de argumentación, no sin un enfoque crítico.

El tema del décimo día de narración en esta colección de novelas son las acciones que dan cuenta de una generosidad extraordinaria ${ }^{34}$. Contrariamente a lo que cabría esperar de un tratamiento moral-filosófico del tema, muchas de las narraciones están repletas de ambigüedades. Esto se advierte repetidas veces en la famosa novela de Griselda ${ }^{35}$, pero también en la novela que ahora vamos a exa-

31. Véase Boccaccio, Genealogia, XIV, 4, 12: «Leges autem non sic; non equo iure vivit cum Ethyope Sauromata, non eadem legum autoritas bello laborantibus atque leta pace quietis. Nec non augent, sepe minuuntque plurimum potestatis instituta municipalia legibus constitutionesque regnorum; facit illas indictum iustitium mutas. Senescunt etiam et moriuntur aliquando, nam non nulle iam dudum in pretio fuere permaximo, que evo nostro aut neglecte sunt, aut omnino abolite; et sic non idem semper sunt, ut comperta poesis».

32. Dante, Purgatorio, VI, 139-144: «Atene e Lacedemona, che fenno / I'antiche leggi e furon sì civili, / fecero al viver bene un picciol cenno / verso di te [sc. Fiorenza mia], che fai tanto sottili / provedimenti, ch'a mezzo novembre non giugne quel che tu d'ottobre fili».

33. Boccaccio, De casibus virorum illustrium, III, 10.

34. El décimo día se introduce con las palabras «incominicia la Decima e ultima [giornata], nella quale, sotto il reggimento di Panfilo, si ragiona di chi liberalmente o vero magnificamente alcuma cosa operasse intorno a' fatti d'amore o d'altra cosa».

35. La novela de Griselda ha dado lugar a una gran variedad de interpretaciones y sigue desconcertando a sus lectores hasta el día de hoy. Klinkert (2010, p. 55), citando la literatura de investigación más relevante, formula: «Der Hinweis auf die Widersprüchlichkeit der Griselda-Novelle und die daraus resul- 
minar, que versa sobre la (supuesta) «magnificencia» $(\S 4)^{36}$ de Messer Gentile. Una proto-forma, menos refinada de esta novela se encuentra en la 13. ${ }^{a}$ questione d'amore del Filocolo, que muestra igualmente la conexión, antes señalada, entre la disputatio legal, la cuestión amorosa y el género de la novela ${ }^{37}$.

Con carácter previo a un análisis en detalle de la novela, resulta preciso presentar brevemente su contenido:

Gentile de' Carisendi ama a Madonna Catalina, la esposa de Niccoluccio Caccianemico. Sin embargo, como su amor no es correspondido, deja Bolonia y toma el cargo de Podestà en Módena. Catalina, que estaba embarazada, cae gravemente enferma, un médico certifica su muerte y recibe sepultura. Cuando Gentile se entera de esto, se dirige en secreto a su tumba para robarle el beso que ella siempre le había negado en vida. Pero no se detiene en el beso, y, al tocar su pecho, siente un débil latido. En estas, lleva a Catalina a su casa, donde su madre se ofrece para cuidarla, y da a luz a un hijo que Gentile hace bautizar con su mismo nombre - Gentile-. Tiempo después, organiza una gran fiesta en la que, ante los ojos de la nobleza de Bolonia, entrega a Niccoluccio a su esposa Catalina junto con el niño, como muestra de su generosidad.

La novela está ambientada en Bolonia, el centro de los estudios jurídicos en el medioevo. Al principio de la historia, el protagonista, Gentile de' Carisendi, toma el cargo de Podestà en la vecina Módena. Si bien el cargo de Podestà no exigía ser jurista, pues tenía tras de sí toda una famiglia de abogados, notarios y policías, el designado devenía responsable de la justicia y el orden público de su municipio. La novela se sitúa así en un ambiente legal desde el principio.

La atención hay que situarla sobre las acciones de Gentile. El protagonista degrada a Catalina a un objeto silencioso, y controla manipuladoramente a su marido, Niccoluccio. Gentile se caracteriza por un fuerte deseo de poder, que la narradora, Lauretta, enfatiza a través del uso repetido de los verbos ordinare y volere. Se distingue por su talento retórico y su dominio de un discurso legal y teológico. Su talento para el lenguaje, su falta de escrúpulos y su impavidez ante lo trascendente recuerdan a Ser Cepparello, el malvado notario de la primera novela del Decamerón, que se transforma en un santo en su hipócrita confesión, ya en el lecho de muerte ${ }^{38}$. La decisión de Gentile de profanar la tumba no está patrocinada por titubeos morales, sino por un pragmatico utilitarismo: «Ecco, madonna Catalina, tu se' morta: io, mentre che vivesti, mai un solo sguardo da te aver non potei; per che, ora che difender non ti potrai, convien per certo che, cosí morta come tu se', io alcun bascio ti tolga» (§ 8). La frase «ora che difender non potrai», así como el verbo togliere,

tierende Divergenz der Interpretationen besitzt in der Forschungsliteratur topischen Charakter». Sobre la ambigüedad del Decamerón ver Doering, en prensa.

36. Las indicaciones entre paréntesis se refieren a la división del texto en párrafos hecha por Vittore Branca.

37. Una comparación de la Quaestio XIII y la novela X, 4 la lleva a cabo Dutschke, 1975, pp. 300-312.

38. El paralelismo entre Gentile de' Carisendi y Ser Cepparello también lo destaca Dutschke, 1975, p. 312.

En cuanto los aspectos jurídicos de la primera enmienda, en particular la forma des confessio, véase Doering, 2020, pp. 40-59. 
acentúan la violencia de su propósito. La posibilidad de decidir sobre un cadáver se ha utilizado, desde la antigüedad, en contextos políticos, como signo de victoria y como prueba de la superioridad física ${ }^{39}$. Gentile transfiere, en ese instante, esta forma de demostración de poder a la esfera privada del amor. En el curso de la novela, sin embargo, Catalina pasa de constituir un objeto de amor a simple una moneda de cambio con la que Gentile puede alcanzar una posición de poder en la alta sociedad de Bolonia ${ }^{40}$.

Con la ayuda de las formas legales del casus y la quaestio, Gentile logra resignificar su escandalosa afrenta como un acto de caridad cristiana. Antes de que la fiesta se entere del destino de Catalina y Gentile la entregue a su marido, como regalo, se plantea una cuestión dudosa («un dubio», § 25), para que los presentes la juzguen:

[...] vi priego mi diciate quello che sentite d'un dubbio il quale io vi moverò. Egli è alcuna persona la quale ha in casa un suo buono e fedelissimo servidore, il quale inferma gravemente; questo cotale, senza attendere la fine del servo infermo, il fa portare nel mezzo della strada né piú ha cura di lui; viene uno strano, e mosso a compassione delio 'nfermo, e sel reca a casa e con gran sollecitudine e con ispesa il torna nella prima sanità. Vorrei io ora sapere se, tenendolsi ed usando i suoi servigi, il suo signore si può a buona equità dolere o ramaricare del secondo, se egli raddomandandolo rendere nol volesse (§§ 26-27).

Gentile compara lo sucedido con otro casus. El problema, sin embargo, es que la comparación es defectuosa en más de un aspecto. Esta se formula con la intención de resignificar positivamente su propia acción impúdica. Al recurrir a la relación amo-criado, pero no a los complejos vínculos del matrimonio, que es a la vez un contrato y un sacramento, las cuestiones de Derecho matrimonial se soslayan por completo. Gentile asigna a Catalina el papel de un sirviente devoto sin voluntad propia. El marido de Catalina, Niccoluccio, es retratado como el amo que actúa maliciosamente cuando hace que su criado gravemente enfermo sea echado a la calle sin esperar a su muerte. También en este punto, la presentación del caso se desvía claramente de los eventos previamente narrados. Por un lado, Catalina había caído enferma en ausencia de su marido, que en ningún momento se apartó de ella a causa de su enfermedad; y por el otro, su muerte es certificada por un médico, antes de su entierro ${ }^{41}$, a fin de que sus parientes pudieran darle sepultura con la

39. Véase Schmitz-Esser, 2014, pp. 544-554.

40. En su perpicaz análisis de la novela, Moe, 1995, p. 633, anota: «Catalina's status in the economy of the tale shifts from an object of desire to an object of exchange. In both cases she is an object, lacking in subjectivity and literally reified - first as a corpse, then as a gift- but it is only in the second instance that she is actually turned into an instrument to be used in Carisendi's endeavor to increase his social status and power».

41. Además de una sofisticada crítica de los juristas, el Decamerón también contiene pasajes en los que repetidamente se pone en tela de juicio el conocimiento médico, como, por ejemplo, el fragmento en el que los médicos se encuentran indefensos ante la peste. 
certeza de su fallecimiento. Mientras que las acciones del amo/marido son resultado de la malicia y la falta de amor, Gentile se arroga -en la figura de un extraño que pasa por allí- el impulso que motiva la compassio («mosso a compassione»).

Su deseo sexual desmedido, que le lleva a cometer un acto de necrofilia, queda resignificado como un acto de caridad cristiana. De este modo, el casus permite difuminar la afrenta que supone la profanación del cadáver y reconducir el acto hacia el estándar de una buena conducta ${ }^{42}$. Gentile deriva del caso una pregunta (quaestio), con cuya respuesta pretende fundamentar su pretensión (jurídica) a que se le entregue la esposa de Niccoluccio. Pregunta a los presentes si el amo tendría fundados motivos para quejarse («a buona equità»), si el extraño se quedase con el criado sanado gracias a sus cuidados y rehusase devolvérselo. Los invitados discuten el caso y llegan a la unánime conclusión («sentencia», § 28) de que el sirviente se ha convertido, justamente («giustamente», § 29), en propiedad del extraño. La manipulación tiene éxito, porque los invitados desconocen los hechos que realmente acaecieron en la tumba, juzgando exclusivamente el caso que Gentile les presenta. De acuerdo con el plan de Gentile, nombran a Niccoluccio, de entre todos, para que pronuncie el veredicto.

Tras exhibir a Catalina y al niño, Gentile hace una interpretación religiosa del caso, que se convierte así en una parábola:

Signori, questa donna è quello leale e fedel servo del quale io poco avanti vi fe' la dimanda; la quale da' suoi poco avuta cara e cosí come vile e piú non utile nel mezzo della strada gittata, da me fu ricolta e colla mia sollecitudine ed opera delle mani la trassi alla morte: e Iddio, alla mia buona affezion riguardando, di corpo spaventevole cosí bella divenir me l'ha fatta (§ 38).

Gentile identifica a Catalina como la sirvienta fiel del caso al que recurrió como comparación. En cuanto al amo, evita insinuar que se trata de Niccoluccio y habla abiertamente "da' suoi», refiriéndose así a toda la familia de la señora. Los parientes, entre los cuales se encuentra su marido, son acusados de desamor. La salvación de Catalina, en cambio, se interpreta como una buena obra basada en el amor puro («buona affezion»). Como testigo de sus buenas intenciones, Gentile cita a Dios, quien miró en su interior («alla mia buona affezion riguardando») y permitió así que el espantoso cuerpo sin vida se transformase en la bella dama viviente. Gentile describe así su afrenta inmoral no solo como un mandato legal, sino también como una orden divina. Como conclusión, formula su pretensión (jurídica) de que le entreguen a la mujer: «Per le quali cose, se mutata non avete sentenzia da poco in qua, e Niccoluccio spezialmente, questa donna meritamente è mia, né alcuno con giusto titolo la mi può raddomandare» (§ 40). Al igual que en el empleo del casus y la quaestio, la elección de palabras de Gentile («con giusto titolo») demuestra su dominio del discurso jurídico y el uso que de él hace para sus propios fines.

42. Moe (1995, p. 631) subraya el poder de transformación que trae consigo la presentación del casus: «There, through a legalistic representation of his encounter with Catalina, he [scilicet Gentile] succeeds in transforming what has thus far been a narrative of excess desire into one of law and social order». 
La sentencia dictada por Niccoluccio y los demás miembros de la sociedad boloñesa sobre el casus debe ahora repetirse, a la vista de lo "realmente" sucedido, si no quieren ser tildados de volubles, adjudicando Catalina a Gentile. Sin embargo, antes de que la sociedad tenga tiempo para comentar nada, Gentile vuelve a tomar la palabra y, en un acto de simbólica generosidad, entrega a Catalina y al niño a Niccoluccio:

ma messer Gentile, levatosi in piè e preso nelle sue braccia il piccol fanciullino e la donna per la mano, ed andato verso Niccoluccio, disse: Leva su, compare; io non ti rendo tua mogliere, la quale i tuoi e suoi parenti gittarono via, ma io ti voglio donare questa donna mia comare con questo suo figlioletto, il qual son certo che fu da te generato e il quale io a battesimo tenni, e nomina'lo Gentile (§ 42).

Según el plan de Gentile, la entrega ceremonial tiene lugar ante los ciudadanos más respetados de Bolonia («io intendo di voi [scilicet Catalina], in presenzia de' migliori cittadini di questa terra, fare un caro ed un solenne dono al vostro marito», $\S 20)$. El hecho de que Gentile se levante y le pida a Niccoluccio que se levante también evoca cierto simbolismo, que se plasma en el lenguaje corporal. En la escena que sigue aparece la habilidad de Gentile para resignificar las cosas y circunstancias a su conveniencia, y así crear una nueva realidad social. El casus y su evaluación por los presentes le permiten devolver a Catalina a Niccoluccio no por obligación legal («io non ti rendo tua moglie»), sino como un regalo tan voluntario como generoso («ma io ti voglio donare questa donna»). Así adquiere un papel de padrino, que no le es asignado por los padres como era costumbre, sino que se lo arroga a sí mismo; lo que le permite resignificar todavía más las cosas: si bien en la Italia medieval se solían poner los nombres de los parientes cercanos que habían fallecido, hace bautizar al niño con el nombre de Gentile, para así quedar lingüísticamente presente en la familia Caccianemico en el presente y en el futuro ${ }^{43}$. Asumir el papel de padrino no sólo le permite establecer una conexión de por vida con su ahijado, sino también con los padres del niño. El padrinazgo, es decir, la relación social entre el padrino de un niño y sus padres, fue de gran importancia en la Baja Edad Media ${ }^{44}$. Los padres normalmente elegían padrinos con los que querían vincular no tanto al recién bautizado como a ellos mismos a nivel social. La paternidad estaba envuelta de un vocabulario familiar (por ejemplo, compater, pater spiritualis o patrinus) y constituía la manera más flexible y extendida de crear artificialmente relaciones de parentesco ${ }^{45}$. Gentile insiste en las relaciones de parentesco que acaba de establecer en el discurso público en el que se dirige a Niccoluccio como «compare» y se

43. En principio, la transferencia del propio nombre al ahijado se consideraba una distinción en la Edad Media. La decision de nombrar al niño con un padrino la toman los padres, que pueden así ponderar a los padrinos y dar a uno de ellos el honor especial del apellido. Ver Rolker, 2011, pp. 33-34. Sin embargo, Klapisch-Zuber (1985, pp. 57-58) muestra que, a diferencia de Inglaterra y Francia, los niños en Italia muy raramente son nombrados en honor a sus padrinos, sino que domina la idea de mantener vivos a los parientes fallecidos continuando el nombre.

44. Según Rolker (2017), a finales de la Edad Media y principios del periodo moderno, el padrinazgo era más importante que el parentesco.

45. Véase Jussen, 1993. 
refiere a Catalina como «mia comare». La construcción, a través del padrinazgo, de un vínculo estable entre las familias Carisendi y Caccianemico marca la conclusión de la novela, según la cual Gentile permaneció «para siempre» como amigo de Niccoluccio, su esposa, y sus respectivos parientes («e messer Gentile sempre amico visse di Niccoluccio e de' suoi parenti e di quei della donna», § 46).

Gentile instrumentaliza así las practicas legales y religiosas, primero, para encubrir la afrenta sexual y resignificarla como un acto de caritas cristiana, y luego para ocupar permanentemente una posición de alto rango en la sociedad boloñesa.

\section{CONCLUSIÓN}

El ejemplo de la novela $X, 4$ demuestra la compleja posición que la literatura tardomedieval mantuvo en relación con el Derecho, y la profunda crítica que llega a hacer de las prácticas jurídicas.

La novela en sí representa un desarrollo ulterior de las formas de disputa legal. Prueba de ello es la proto-forma que aparece en la 13. ${ }^{\text {a }}$ Questione d'amore, de Filocolo. Aquí la salvación de una mujer embarazada, enterrada viva por su pretendiente, y su posterior regreso a su marido forman el casus del que se deriva la pregunta a juzgar por el público sobre qué debía valorarse más: la honestidad de un caballero o la alegría del marido al ver de nuevo a su esposa y al recién nacido ${ }^{46}$. El caso del sirviente presentado por Gentile no ocurre en el Filocolo. En el Decamerón, Boccaccio plantea el casus de la mujer enterrada viva y su salvación como novela. Pero, a diferencia del caso legal, la novela no termina formalmente en una pregunta, sino que la historia desemboca en una conclusión. Con todo, la novela contiene claras ambivalencias que, a su vez, abren nuevas preguntas. Particularmente problemático se antoja el caso del sirviente repudiado que se recoge por primera vez en la novela. Gracias a él, el Podestà Gentile de' Carisendi puede resignificar el acto transgresor de la necrofilia como un acto de caridad cristiana y mejorar su posición social a largo plazo, forjando nuevos lazos sociales. Al poner en boca de su manipulador protagonista el lenguaje jurídico y el estilo argumental, la novela despliega tópicos de la crítica literaria a los juristas, incluyendo el sometimiento del afecto y la ambición de poder de los estudiosos del Derecho, así como su instrumentalización amoral del lenguaje y la retórica.

46. Véase Boccaccio, Filocolo, IV, 67, 23: «Per che si dubita qual fosse maggiore, o la lealtà del cavaliere o I'allegrezza del marito, che la donna e 'I figliuolo, i quali perduti riputava sì come morti, si trovò racquistati, priegovi che quello che di ciò giudicherete ne diciate». 


\section{BiBLIOGRAFÍA}

Boccaccio, Giovanni, Filocolo, en Tutte le opere di Giovanni Boccacio, ed. Vittore Branca, vol. 1, Milano, Mondadori, 1967.

Boccaccio, Giovanni, De casibus virorum illustrium, ed. Pier Giorgio Ricci y Vittorio Zaccaria, en Tutte le opere di Giovanni Boccaccio, ed. Vittore Branca, vol. 9, Milano, Mondadori, 1983.

Boccaccio, Giovanni, Decameron, ed. Vittore Branca, Turino, Einaudi, 1980, 2 vols.

Boccaccio, Giovanni, Genealogia deorum gentilium, ed. Vittorio Zaccaria, en Tutte le opere di Giovanni Boccaccio, ed. Vittore Branca, vol. 7/8, 2, Milano, Mondadori, 1998.

Cicero, Marcus Tullius, Gespräche in Tuskulum, ed. Olof Gigon, Berlin, Artemis \& Winkler, 2003.

Corpus luris Civilis. Die Institutionen, Text und Übersetzung, ed. Okko Behrends, Rolf Knütel, Berthold Kupisch y Hans Hermann Seiler, 2. ${ }^{a}$ ed., Heidelberg, C. F. Müller, 1999.

Dante Alighieri, La Divina Commedia. Purgatorio, commento di Anna Maria Chiavacci Leonardi, Milano, Mondadori, 1994.

De Boer, Jan-Hendryk, «Disputation, quaestio disputata», en Universitäre Gelehrtenkultur vom 13.-76. Jahrhundert. Ein interdisziplinäres Quellen- und Methodenhandbuch, ed. Jan-Hendryk de Boer, Marian Füssel y Maximilian Schuh, Stuttgart, Steiner, 2018, pp. 221-254.

De Propris, Fabio, «Giacomo da Lentini», en Dizionario Biografico degli Italiani, vol. 54, 2000, en línea [consulta: 07/09/2018].

Dionisotti, Carlo, Chierici e laici. Con una lettera di Delio Cantimori, Novara, Interlinea, 1995.

Doering, Pia Claudia, Praktiken des Rechts in Boccaccios «Decameron». Die novellistische Analyse juristischer Erkenntniswege, Berlin, Erich Schmidt, 2020.

Doering, Pia Claudia, «Reichweiten und Grenzen literarischer Ambiguität: Giovanni Boccaccio, Christine de Pizan, Marguerite de Navarre», en Reichweiten. Dynamiken und Grenzen kultureller Transferprozesse in Europa, 1400-1520, vol. 2, ed. Frank Rexroth et al., Berlin / Boston, De Gruyter, en prensa.

Dutschke, Dennis, «Boccaccio: a Question of Love (A Comparative Study of Filocolo IV, 13 and Decameron X, 4)», en The Humanities Association Review, 26, 1975, pp. 300-312.

Emmelius, Caroline, Gesellige Ordnung. Literarische Konzeptionen von geselliger Kommunikation in Mittelalter und Früher Neuzeit, Berlin / New York, De Gruyter, 2010. 
Fried, Johannes, Die Entstehung des Juristenstandes im 12. Jahrhundert. Zur sozialen Stellung und politischen Bedeutung gelehrter Juristen in Bologna und Modena, Köln, Böhlau, 1974.

Friedrich, Hugo, Epochen der italienischen Lyrik, Frankfurt am Main, Klostermann, 1964.

Gilli, Patrick, La Noblesse du droit. Débats et controverses sur la culture juridique et le rôle des juristes dans I'Italie médiévale (XIIe-Xve siècles), Paris, Honoré Champion, 2003.

Jussen, Bernhard, «Patenschaft», en Lexikon des Mittelalters, vol. 6, München, Artemis \& Winkler, 1993, cols. 1779-1780.

Kapp, Volker, Italienische Literaturgeschichte, 3. ${ }^{a}$ ed., Stuttgart, Metzler, 2007.

Klapisch-Zuber, Christiane, «Parrains et filleuls. Une approche comparée de la France, I'Angleterre et l'Italie médiévales», Medieval Prosopography, 6.2, 1985, pp. 51-77.

Klinkert, Thomas, «Die italienische Griselda-Rezeption im 14. und 15. Jahrhundert», en Die deutsche Griselda. Transformationen einer literarischen Figuration von Boccaccio bis zur Moderne, ed. Achim Aurnhammer y Hans-Jochen Schiewer, Berlin / New York, De Gruyter, 2010, pp. 55-72.

Lange, Hermann, «Vom Adel des doctor», en Das Profil des Juristen in der Europäischen Tradition. Symposion aus Anlaß des 70. Geburtstags von Franz Wieacker, ed. Klaus Luig y Detlef Liebs, Ebelsbach, Gremer, 1980, pp. 279-294.

Lange, Hermann, Recht und Macht. Politische Streitigkeiten im Spätmittelalter, Frankfurt am Main, Klostermann, 2010.

Moe, Nelson, «Not a Love Story: Sexual Aggression, Law and Order in Decameron X, 4», The Romanic Review, 86.4, 1995, pp. 623-638.

Neuschäfer, Hans-Jörg, Boccaccio und der Beginn der Novelle. Strukturen der Kurzerzählung auf der Schwelle zwischen Mittelalter und Neuzeit, München, Fink, 1969.

Petrarca, Francesco, Le Familiari, trad. y ed. Ugo Dotti, Turino, Argano, 2004-2009, 5 vols.

Rath, Wolfgang, Die Novelle. Konzept und Geschichte, 2. ${ }^{\text {a }}$ ed., Göttingen, Vandenhoeck \& Ruprecht, 2008.

Rexroth, Frank, Fröhliche Scholastik. Die Wissenschaftsrevolution des Mittelalters, München, Beck, 2018.

Rolker, Christof, «Patenschaft und Namengebung im späten Mittelalter», en Konkurrierende Zugehörigkeiten. Praktiken der Namengebung im europäischen Vergleich, ed. Christof Rolker y Gabriela Signori, Konstanz, UVK, 2011, pp. 17-38. 
Rolker Christof, «Patenschaft, Pate», en Handwörterbuch zur deutschen Rechtsgeschichte, vol. IV, 2017, cols. 422-424, en línea [consulta: 02/12/2020].

Schmitz-Esser, Romedio, Der Leichnam im Mittelalter. Einbalsamierung, Verbrennung und die kulturelle Konstruktion des toten Körpers, Ostfildern, Thorbecke, 2014.

Von Hülsen-Esch, Andrea, Gelehrte im Bild. Repräsentation, Darstellung und Wahrnehmung einer sozialen Gruppe im Mittelalter, Göttingen, Vandenhoeck \& Ruprecht, 2006. 